\title{
NIF Frequently Asked Questions
}

\author{
J. Carpenter, B. Warner
}

September 15, 2000

U.S. Department of Energy

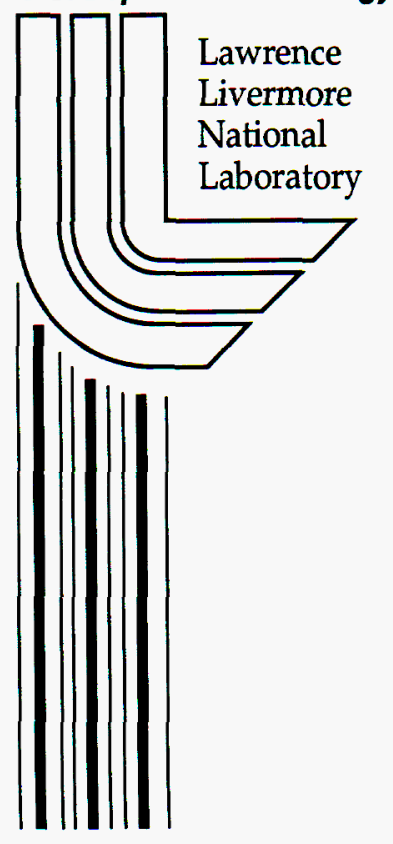




\section{DISCLAIMER}

This document was prepared as an account of work sponsored by an agency of the United States Government. Neither the United States Government nor the University of California nor any of their employees, makes any warranty, express or implied, or assumes any legal liability or responsibility for the accuracy, completeness, or usefulness of any information, apparatus, product, or process disclosed, or represents that its use would not infringe privately owned rights. Reference herein to any specific commercial product, process, or service by trade name, trademark, manufacturer, or otherwise, does not necessarily constitute or imply its endorsement, recommendation, or favoring by the United States Government or the University of California. The views and opinions of authors expressed herein do not necessarily state or reflect those of the United States Government or the University of California, and shall not be used for advertising or product endorsement purposes.

This work was performed under the auspices of the U. S. Department of Energy by the University of California, Lawrence Livermore National Laboratory under Contract No. W-7405-Eng-48. 



\section{NIF FREQUENTLY AsKed Questions}

\section{What is stockpile stewardship?}

The Stockpile Stewardship Program is an initiative to maintain the nuclear deterrent of the United States in the postCold War era. It is based on the maintenance of our stockpile through an ongoing process of surveillance, assessment, refurbishment, and recertification, without nuclear testing. At the heart of the SSP is an attempt to bring advanced experimental and computational tools to bear on the evaluation and certification of the stockpile itself; these advanced scientific capabilities are necessary because of the cessation of nuclear testing. This science-based approach requires new tools: advanced computers for more detailed 3-D simulations, multiaxis hydrodynamic facilities and plutonium research facilities for physics measurements of primaries, and the National Ignition Facility for fusion burn and highenergy-density science. The science basis requires summing up the pieces we can measure and simulate, which cannot be done without a complete set of tools. Refurbishing weapons with confidence, without testing, is a difficult challenge. Only with high-quality scientists and a complete set of tools, can the US accomplish this program.

\section{What is NIF's role in stockpile stewardship?}

NIF is a unique element of the Stockpile Stewardship Program because it is the only facility that will allow the experimental study of thermonuclear burn and important regimes of high-energy-density science. Understanding these phenomena is critical to understanding how modern nuclear weapons work. NIF supports the Stockpile Stewardship Program in three essential ways:

1. It permits the study of issues that can affect an aging or refurbished stockpile.

2. It permits advancement of the critical elements of the underlying science of nuclear weapons.

3. It will attract and help train the exceptional scientific and technical talent required to sustain Stockpile Stewardship over the long term.

\section{Is NIF essential to stockpile stewardship?}

Yes. NIF is a unique facility for experimental study of thermonuclear burn and high-energy-density phenomena that occur in modern nuclear weapons. Thermonuclear burn is at the very heart of how our stockpile works, and the inability to experimentally study physical phenomena in this physical regime would lead to reduced confidence in the US nuclear weapons stockpile.

\section{How would a delay in NIF affect stockpile stewardship?}

Stockpile stewardship is a race against time. The oldest nuclear weapon in the stockpile was added to the stockpile in 1970. That makes the weapon 30 years old. Few people own a car or refrigerator of that vintage.

Efforts to maintain and refurbish aging nuclear weapons over the coming decade will raise questions that will require data from NIF to answer. If NIF is not on line when these questions arise, the nation will have to accept the risk of incomplete certifications or employ expensive risk mitigation strategies until 
the questions can be adequately answered.

Each year, the National Laboratories must evaluate the surveillance information available on each weapon system in the stockpile and recertify that the weapon system is still safe, secure, and reliable. This is the annual certification process. When surveillance data raise questions about a particular weapon's performance, the Laboratories analyze the problem/ issue, conduct experiments to access the significance of the problem/issue, run complex simulations, and finally make a judgement as to their continuing confidence in the weapon system. NIF is designed to fill a critical role as a tool to use in these assessments, and its absence will reduce our ability to have high confidence in the stockpile. Although not all questions that arise will require data from NIF, many past issues would have required NIF if we had not tested, and it is inevitable that future ones will as well.

The weapons life-extension programs that are scheduled to be completed before NIF is fully operational will benefit later in the decade from NIF when their status is reviewed through the annual certification process. Post-deployment evaluations of US nuclear weapons systems using newly available tools have historically been important elements of maintaining stockpile integrity, and have led to a number of refurbishment actions.

\section{Are there any NIF success stories?}

Five Major Technological Breakthroughs. NIF will be 60 times more powerful than its predecessor, Nova, at one-sixth the cost per unit of energy gener-ated. This advancement has required six major breakthroughs in technology: faster, less expensive laser glass production, large-aperture optical switches, stable high-gain preamplifiers, servo-controlled large-aperture deformable mirrors, large rapid-growth frequency-conversion crystals, and long-life final-stage optics.
Livermore Laboratory in collaboration with industry has now successfully developed five of these breakthrough technologies, and we are making good progress on the sixth - the final-stage optics. We recently grew the world's largest rapid-growth crystal, weighing 701 pounds, in 2 months. In the past, growing a crystal of this size and quality would have taken 2 years. The Livermore Lab crystals will produce twice the number of planned frequency-conversion components, decreasing the number of required crystals for NIF.

In addition, our recent pilotproduction run at Schott Glass Technologies in Duryea, PA was particularly successful. The initial run yielded 200 glass slabs or $5 \%$ of the total glass required. These glass slabs meet all technical specifications. We anticipate similar success later this year with our other vendor, Hoya Optics in Fremont, CA. Before the manufacturers' technological breakthroughs, high-quality glass had not been produced in a bulk process. Previously, each piece of glass had to be individually manufactured, an expensive and lengthy process.

The Conventional Facilities Are on Schedule and Meet the Demanding Requirements of NIF. The conventional facilities are at $87 \%$ completion, on schedule and budget. The conventional facilities include the Optics Assembly Building, the Laser Building, and the Target Area Building. The demanding requirements of the NIF laser and target systems led to unusual features in these buildings. For instance, the 25,000square-ft Optics Assembly Building has a large receiving area and three connected clean rooms. This facility receives optics and laser components, and then stores and assembles the components in rooms with stringent cleanliness controls. This building is complete, it is clean, and it has been transferred to Lawrence Livermore for outfitting of special equipment.

The Laser Building is approximately $600 \mathrm{ft}$ long and $400 \mathrm{ft}$ wide. It houses two laser bays that each contains 96 of the 192 beams of the NIF laser. The lasers must be pointed very precisely. This pointing requirement is equivalent to using the point of a needle to touch a single human hair from 100 yards away. This pointing precision contributes to a number of unusual requirements relating to stability and vibration for the Laser Building. For stability, the laser system is supported on concrete pedestals that are mounted on $400-\mathrm{ft}-$ long by 80 -ft-wide by 3 -ft-thick singlepour concrete slabs. The laser building will be temperature-controlled to one-half degree Fahrenheit to maintain laser positioning. This in turn requires 15 full air changes per hour and sophisticated air-handling systems that have very low vibration. The Laser Building is now very close to completion, and will start accepting large steel laser vessels later this year.

The Target Area Building contains ten-story steel structures that hold the large turning mirrors that direct the laser beams toward the target. Again, these structures must be very stable and resistant to vibration. Consequently, the steel structures are robust, and in addition, are anchored into the building, resulting in the stiffest structures of this size ever built. One of the two switchyards is now complete; the second is nearing completion. At the center of the Target Area Building is the 33-ft-diameter target chamber. For stability reasons, the target chamber is an integral part of the Target Area Building concrete structure. This concrete structure includes 6-ft-thick walls surrounding the chamber for radiation protection. The Target Area Building is nearing completion. The roof will be completed in the next several weeks, followed by completion of ventilation and electrical service.

Questions concerning the National Ignition Facility at LLNL should be directed to the LLNL Public Affairs Office, (925) 422-9919. 